\title{
Seed cryopreservation of Fraxinus angustifolia Vahl
}

\author{
Giovanna Lombardo $^{1 *}$, Anna Scialabba ${ }^{1}$ and Rosario Schicchi ${ }^{2}$ \\ ${ }^{1}$ Dipartimento di Scienze e Tecnologie Biologiche, Chimiche e Farmaceutiche (STEBICEF), Plesso di Botanica, \\ Università degli Studi di Palermo, via Archirafi 38, 90123 Palermo, Italy. \\ ${ }^{2}$ Dipartimento di Scienze Agrarie e Forestali, Plesso di Botanica, Università degli Studi di Palermo, via Archirafi 38, \\ 90123 Palermo, Italy. \\ Accepted 25 March, 2013

\begin{abstract}
Fraxinus angustifolia is used for afforestation and for production of both valuable timber and manna, a substance with pharmacological applications. The aim of this research was to establish the optimized condition for cryopreservation of $F$. angustifolia seeds, in order to protect the germplasm of this species. Germination percentage and mean time of germination of non-treated seeds (control) and liquid nitrogen-treated seeds were established in water or in $10^{-6} \mathrm{M}$ gibberellic acid $\left(\mathrm{GA}_{3}\right)$. The seeds could be cryopreserved with $3 \%$ of moisture content (MC) and germinated easily in water $(70.0 \pm 5.0 \%)$, while seeds cryopreserved with $6 \%$ MC showed a physiological dormancy. This state could be efficiently removed by addition of $\mathrm{GA}_{3}$, which increased germination to $76.0 \pm 2.4 \%$. Liquid nitrogen did not impair embryo viability, allowing a successful cryopreservation of seeds. The results are particularly useful for both germplasm conservation programs and in narrow leaved ash nurseries.
\end{abstract}

Key words: Fraxinus angustifolia, germination, germplasm conservation, seed cryopreservation.

\section{INTRODUCTION}

Fraxinus angustifolia Vahl (narrow leaved ash) is a woody species used in afforestation and production of valuable timber. In Sicily (Italy), this species is cultivated together with Fraxinus ornus L. to produce the "manna" (llardi and Raimondo, 1999), a solidified phloem sap collected from artificial incisions on the trunks. Manna has many pharmacological applications (Schicchi et al., 2006). Ash cultivations for manna production are located exclusively in small areas of Castelbuono and Pollina (Palermo, Sicily) and are gradually disappearing since this activity is mainly carried out by old farmers. Some ash individuals are very ancient and so big to be considered monumental. In the district of Puntaloro (Petralia Sottana, Palermo), there is one of the oldest specimens of $F$. angustifolia in Italy. This individual is 400 years old, $28 \mathrm{~m}$ high and has a trunk of $7.5 \mathrm{~m}$ round. Pests, diseases and environmental adversities negatively and severely influence the growth of this monumental ash, making necessary a specific preservation strategy by ex situ conservation methods and techniques which allow its re-introduction in nature.

The storage of biological material in liquid nitrogen (Brearley et al., 1995) is the best method currently used to preserve and store genetic resources for long-term ex situ conservation. It has been suggested that the extremely low temperature of liquid nitrogen $\left(-196^{\circ} \mathrm{C}\right)$ arrest cell metabolism (Engelmann, 2004), although some studies have shown a residual activity of some ageing reactions (Walters et al., 2004). Ash seeds are classified as orthodox (Bonner, 2008). The seeds with

*Corresponding author. E-mail: giovanna.lombardo@unipa.it. Tel: ++3909123891224. Fax: ++390916165997.

Abbreviations: Cryo, Cryopreserved seeds; $\mathbf{G A}_{3}$, gibberellic acid; LN, liquid nitrogen; MC, moisture content; MTG, mean time of germination; NT, non-treated seeds; TTC, 2,3,5-triphenyl tetrazolium chloride. 

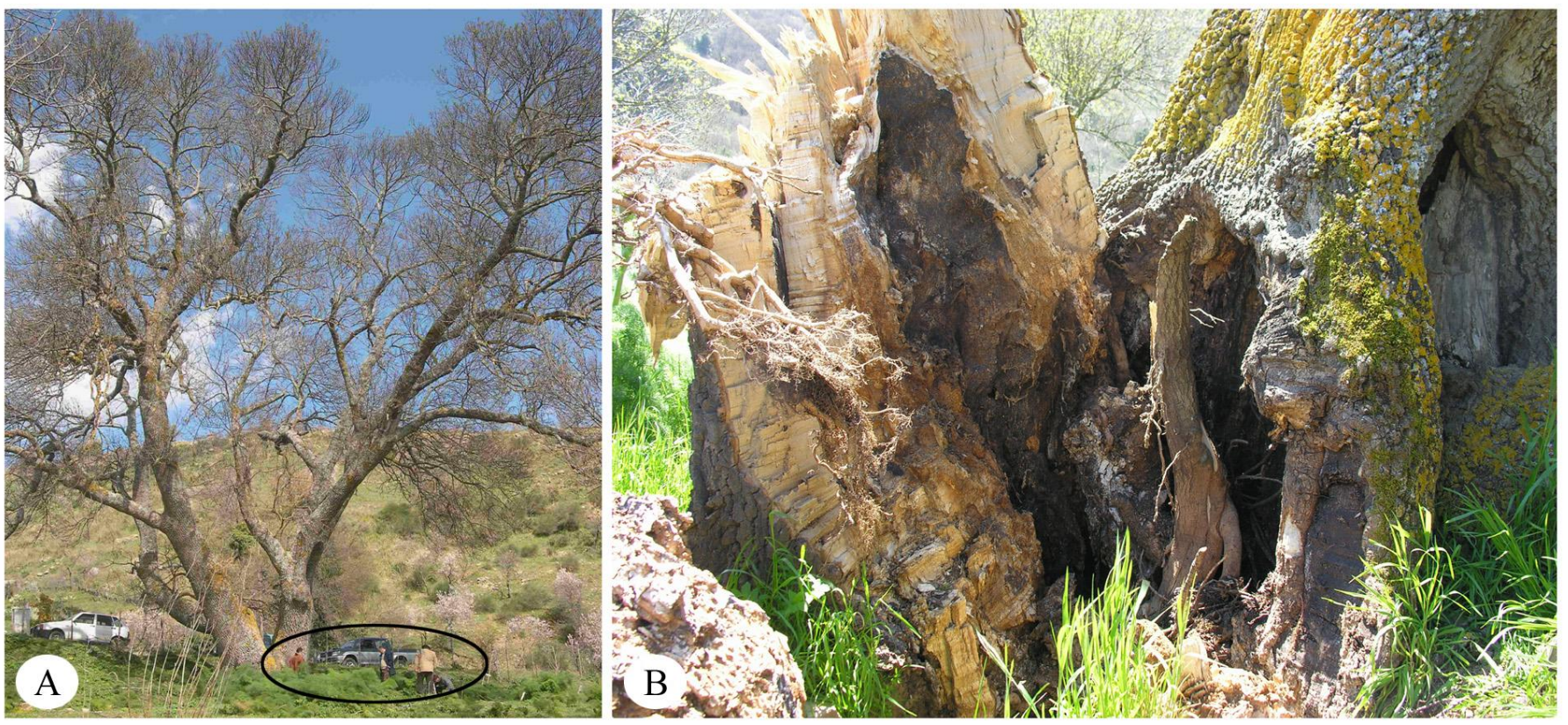

Figure 1. Monumental specimen: 400-year-old $F$. angustifolia $(A)$ and the detail of a breaking point of the trunk (B) due to diseases and environmental adversities. In the circle, the men's size is reference.

orthodox behaviour (Roberts, 1973) represent a good biological type suitable for cryopreservation because they can tolerate freezing without using cryoprotectors (Chetverikova, 2008) as long as they are sufficiently dry (Popov et al., 2006) since the seed moisture content is a critical factor determining the viability and longevity of the seed.

Seeds of Fraxinus excelsior L. can be successfully stored in liquid nitrogen (Chmielarz, 2009), but no information about seed cryopreservation of $F$. angustifolia is available to date. The seeds of the genus Fraxinus undergo different types of dormancy, according to the specific characteristics of the embryo: morphological dormancy or physiological dormancy. The first occurs when the seed is relatively small though morphologically complete, the latter occurs when the seed is still dormant at seed dispersal time; moreover, a delay in germination is often caused by the mechanical resistance offered by the enveloping tissues, that is, endosperm, suberized layer and seed coat (Preece et al., 1995; Steinbauer, 1937). Since the degree of embryo development and the dormancy status of the seed vary considerably among the different species of ash, it is important to assess the most suitable cryopreservation methods for narrow leaved ash seeds.

The aim of this research was to verify the viability of $F$. angustifolia seeds after storage in liquid nitrogen in order to preserve its invaluable germplasm.

\section{MATERIALS AND METHODS}

Mature brown samaras of a monumental tree of $F$. angustifolia, located in Puntaloro (Petralia Sottana), Palermo-Italy (Figure 1), were collected at the end of July (early stage of maturation) and at the middle of November (final stage of maturation) (the blossom occurred in December-January). Seeds were extracted from the fruits and the percentages of seed presence/absence, number of seeds per samara and aborted seeds were evaluated. Seeds were considered aborted when their width was lower than $15 \%$ of the mean width.

The moisture content (MC) of the seeds was measured in five independent replicas of 10 seeds each, by drying at $103 \pm 2^{\circ} \mathrm{C}$ for $18 \mathrm{~h}$, repeating the treatment until seeds had reached constant dry masses. The MC was expressed as percentage of fresh weight. In order to process all seeds at once, seeds harvested in July were stored at $4^{\circ} \mathrm{C}$ with moisture content (MC) of 8 to $10 \%$ until November. Before starting the experiments, the $M C$ was decreased to $6 \%$ in the seeds harvested in July (group 1) and to 3 (group 2) and $6 \%$ (group 3 ) in the seeds harvested in November. In the latter lot, a significantly higher seed number allowed assessment of the influence of two different MC percentages on viability of cryopreserved seeds. The dehydration was performed in sealed jars containing silica gel, previously oven-dried at $130^{\circ} \mathrm{C}$ for $24 \mathrm{~h}$.

The seeds to be cryopreserved (Cryo) were placed in cryovials, plunged directly into liquid nitrogen (LN) and stored for 10 days. After freezing in $\mathrm{LN}$, the cryovials were thawed at $40^{\circ} \mathrm{C}$ in a water bath for $15 \mathrm{~min}$. Non-treated (NT) seeds were used as control. Before starting the germination experiments, NT or cryopreserved seeds from each group, were sterilized by immersion for $1 \mathrm{~min}$ in ethanol (70\% v/v in water), $20 \mathrm{~min}$ in $30 \%$ (v/v in water) commercially-available bleach containing few drops of Tween 20, followed by three rinses with sterile distilled water. The seeds were left imbibed for $24 \mathrm{~h}$ in a laminar flow hood. For germination experiments, seeds were incubated in 9-cm diameter Petri dishes containing four layers of filter paper (Whatman $n^{\circ} 1$ ) and imbibed with $10 \mathrm{ml}$ distilled water (control) or $10^{-6} \mathrm{M} \mathrm{GA}_{3}$ at $20^{\circ} \mathrm{C}$ and $16 / 8 \mathrm{~h}$ of light/darkness and light intensity of $50 \mu \mathrm{mol} / \mathrm{m}^{2} / \mathrm{s}$ provided by Osram cool-white $18 \mathrm{~W}$ fluorescent lamps. Each experiment was performed with 10 seeds and repeated 20 times. To estimate the highest value of germination, germination percentage was recorded 
Table 1. Germination percentage after 30 and 60 incubation days, mean time of germination (MTG) after 30 days of incubation, root and hypocotyl lengths of seedlings developed from 30 days incubated seeds, belonging to the three groups.

\begin{tabular}{|c|c|c|c|c|c|c|}
\hline \multirow{3}{*}{ Group } & \multirow[b]{2}{*}{ Incubation day } & \multicolumn{2}{|c|}{ Germination } & \multirow{2}{*}{$\begin{array}{c}\text { MTG } \\
30 \\
\end{array}$} & \multicolumn{2}{|c|}{ Length } \\
\hline & & 30 & 60 & & Root & Hypocotyl \\
\hline & Treatment & & & & & \\
\hline \multirow{4}{*}{1} & $\mathrm{NT} \mathrm{H}_{2} \mathrm{O}$ & $26.0 \pm 4.0^{a}$ & $26.0 \pm 4.0^{a}$ & $26.0 \pm 4.0^{\mathrm{a}}$ & $27.5 \pm 2.5^{\mathrm{a}}$ & $9.0 \pm 1.0^{a}$ \\
\hline & NT $\mathrm{GA}_{3}$ & $15.7 \pm 1.4^{b}$ & $15.7 \pm 1.4^{b}$ & $15.7 \pm 1.4^{b}$ & $33.4 \pm 3.8^{\mathrm{ab}}$ & $21.1 \pm 2.3^{b d}$ \\
\hline & Cryo $\mathrm{H}_{2} \mathrm{O}$ & $26.7 \pm 3.3^{\mathrm{a}}$ & $26.7 \pm 3.3^{\mathrm{a}}$ & $26.7 \pm 3.3^{a}$ & $20.6 \pm 13.7^{a}$ & $9.6 \pm 4.8^{\mathrm{a}}$ \\
\hline & Cryo $\mathrm{GA}_{3}$ & $18.4 \pm 0.9^{\mathrm{ab}}$ & $18.4 \pm 0.9^{\mathrm{ab}}$ & $18.4 \pm 0.9^{\mathrm{ab}}$ & $32.5 \pm 3.6^{\mathrm{ab}}$ & $17.1 \pm 1.9^{\mathrm{abd}}$ \\
\hline \multirow{4}{*}{2} & $\mathrm{NT} \mathrm{H}_{2} \mathrm{O}$ & $9.8 \pm 0.3^{b}$ & $9.8 \pm 0.3^{b}$ & $9.8 \pm 0.3^{b}$ & $51.5 \pm 7.2^{b}$ & $17.0 \pm 1.3^{\mathrm{abd}}$ \\
\hline & $\mathrm{NT} \mathrm{GA} \mathrm{A}_{3}$ & $10.6 \pm 1.4^{b}$ & $10.6 \pm 1.4^{b}$ & $10.6 \pm 1.4^{b}$ & $38.5 \pm 4.4^{\mathrm{ab}}$ & $23.6 \pm 1.9^{b c}$ \\
\hline & Cryo $\mathrm{H}_{2} \mathrm{O}$ & $9.9 \pm 2.3^{b}$ & $9.9 \pm 2.3^{b}$ & $9.9 \pm 2.3^{b}$ & $46.0 \pm 6.9^{a b}$ & $17.1 \pm 2.8^{\mathrm{abd}}$ \\
\hline & Cryo $\mathrm{GA}_{3}$ & $8.6 \pm 0.6^{b}$ & $8.6 \pm 0.6^{b}$ & $8.6 \pm 0.6^{b}$ & $33.7 \pm 2.6^{\mathrm{ab}}$ & $34.4 \pm 1.3^{\mathrm{C}}$ \\
\hline \multirow{4}{*}{3} & $\mathrm{NT} \mathrm{H}_{2} \mathrm{O}$ & $15.3 \pm 1.2^{b}$ & $15.3 \pm 1.2^{b}$ & $15.3 \pm 1.2^{b}$ & $50.8 \pm 8.2^{b}$ & $11.6 \pm 1.6^{a}$ \\
\hline & $\mathrm{NT} \mathrm{GA} \mathrm{A}_{3}$ & $9.7 \pm 1.5^{\mathrm{b}}$ & $9.7 \pm 1.5^{b}$ & $9.7 \pm 1.5^{\mathrm{b}}$ & $34.6 \pm 2.8^{\mathrm{ab}}$ & $33.7 \pm 2.0^{\mathrm{C}}$ \\
\hline & Cryo $\mathrm{H}_{2} \mathrm{O}$ & $13.0 \pm 2.1^{\mathrm{b}}$ & $13.0 \pm 2.1^{b}$ & $13.0 \pm 2.1^{\mathrm{b}}$ & $42.2 \pm 5.8^{a b}$ & $12.4 \pm 1.4^{\mathrm{a}}$ \\
\hline & Cryo $\mathrm{GA}_{3}$ & $9.5 \pm 0.8^{b}$ & $9.5 \pm 0.8^{b}$ & $9.5 \pm 0.8^{\mathrm{b}}$ & $29.2 \pm 2.7^{\mathrm{a}}$ & $26.9 \pm 1.7^{\mathrm{cd}}$ \\
\hline
\end{tabular}

Mean \pm standard error. Means followed by the same letter are not significantly different at $p<0.05$, according to the Tukey's test. 1, Seeds harvested in July and incubated with $6 \%$ moisture content (MC); 2 , seeds harvested in November and incubated with 3\% MC; 3, seeds harvested in November and incubated with 6\% MC of seeds not treated (NT) or treated in liquid nitrogen (Cryo) incubated in water $\left(\mathrm{H}_{2} \mathrm{O}\right)$ or in $10^{-6} \mathrm{M}$ gibberellic acid $\left(\mathrm{GA}_{3}\right)$.

weekly for 30 days and after 60 days.

Mean time of germination (MTG) was calculated after 30 days and was determined according to the formula: [ $\left.\Sigma n_{i} d_{i} / n\right]$, where $n_{i}$ is the number of seeds that germinated at day $d_{i} ; d_{i}$ is the considered day and $\mathrm{n}$ is the total number of seeds that germinated in the incubation period. Seeds with radicle length of $2 \mathrm{~mm}$ were considered as germinated. After 30 days of incubation, the lengths of roots and hypocotyls in developed seedlings were measured.

After 60 days, non-germinated seeds were stained in 1\% 2,3,5triphenyl tetrazolium chloride (TTC) dissolved in tap water $(\mathrm{pH} 7.0)$ to test their viability (Patil and Dadlani, 1993). Seeds were cut laterally along the longitudinal axes and completely covered with TTC solution. Samples were incubated in the dark at $25 \pm 2^{\circ} \mathrm{C}$ for $20 \mathrm{~h}$, rinsed twice with water and immediately observed under the stereo microscope. Intermediate or white-stained seeds were considered as non-viable, while exclusively red embryos were considered as vital.

To verify the vigour of cryopreserved seeds, 30 to 60 days-old seedlings obtained from cryopreserved seed were transferred in Jiffy ${ }^{\circledR}$ into magenta and incubated at $25^{\circ} \mathrm{C}$ and $16 / 8 \mathrm{~h}$ of light / darkness; when the radical apparatus became visible in the Jiffy ${ }^{\circledR}$, the seedlings were potted, closed in transparent plastic bags and placed in the greenhouse. The plastic bags were perforated gradually to bring the seedlings in full air.

Statistical analyses were performed with Sigmastat 3.5 software. To evaluate the significance of the differences between the mean values, analysis of variance (ANOVA) and Tukey test for pair-wise comparison at $\mathrm{p}<0.05$ were applied.

\section{RESULTS}

Among the seeds collected in July (group 1), $87.7 \%$ of samaras contained one normal seed, $4.5 \%$ two seeds, $2.4 \%$ aborted seeds and $5.4 \%$ were empty. Among the seeds collected in November (groups 2 and 3), the samaras containing one normal seed were $76.6 \%, 7.5 \%$ contained two seeds, $0.4 \%$ three seeds, $7.5 \%$ aborted seeds and $8.0 \%$ of the samaras were empty.

The MC of seeds collected in July $(6.4 \pm 0.1)$ was slightly but significantly $(p<0.001)$ reduced compared to the one of those collected in November $(8.0 \pm 0.1)$.

After 30 days of incubation, the germination percentage (Table 1) of group 1 was very low in water, $4.0 \pm 1.0 \%$ for NT seeds and $6.0 \pm 1.0 \%$ for the Cryo seeds. The $\mathrm{GA}_{3}$ treatment increased the germination percentage to $76.0 \pm$ $2.4 \%$ for NT and $82.0 \pm 2.0 \%$ for the Cryo, which reached the highest percentage of germination. Furthermore, a significant difference between incubation in water or $\mathrm{GA}_{3}$ was registered $(p<0.001)$ while no significant effect of the cryopreservation treatment could be observed. $\mathrm{GA}_{3}$ speed up the germination process, decreasing the MTG by 10.3 days $(p<0.05)$ in NT seeds and 8.3 days in Cryo seeds. Group 2 showed a homogeneous germination percentage ranging from $64.0 \pm 2.0 \%$ (NT in water) to $76.0 \pm 4.0\left(\mathrm{NT}\right.$ in $\left.\mathrm{GA}_{3}\right)$, with an intermediary value of 70.0 $\pm 5.0 \%$ (Cryo seeds in water and $\mathrm{GA}_{3}$ ). No significant difference within these groups was observed. Accordingly, also, the MTG among groups was not significantly different, ranging from 8.6 to 10.6 days. In group 3 , the highest germination percentage was recorded in $\mathrm{GA}_{3}$ treated seeds with values of $74.0 \pm 2.4$ and $76.0 \pm 5.0$, respectively, in NT and Cryo. The plant regulator showed a significant effect $(p<0.001)$ on germination probability over the water incubation, which led to germination percentages ranging from $44.0 \pm 2.4$ (NT) to $56.0 \pm 4.0$ (Cryo). The MTG was lower in seeds incubated in $\mathrm{GA}_{3}(9.7$ and 9.5 
days, respectively, in NT and Cryo seeds), while the MTG in water increased by 5.6 days for NT seeds and 3.5 for Cryo seeds. After 60 days of incubation, the germination percentage slightly increased in all the these except for NT $\mathrm{GA}_{3}$ and Cryo $\mathrm{H}_{2} \mathrm{O}$ of Group 2, and Cryo $\mathrm{GA}_{3}$ of Group 3 (Table 1).

The root length (Table 1) ranged from $20.6 \pm 13.7$ to $51.5 \pm 7.2 \mathrm{~mm}$ and was longer in groups 2 and 3 than group 1, but no significant difference could be observed. The hypocotyl length (Table 1 ) ranged from $9 \pm 1$ to 34.4 $\pm 1.3 \mathrm{~mm}$. In this case, the seeds harvested in November and incubated in $\mathrm{GA}_{3}$ showed a significantly longer hypocotyl as compared to the other treatments. The seedlings belonging to the three groups did not exhibit any morphological difference among the treatments as shown in Figure 2A to D; however, during the development stage, the plantlets originated from seeds incubated in $\mathrm{GA}_{3}$ showed a longer epicotyl (Figure $2 \mathrm{~F}$ ) as compared to those incubated in water (Figure 2E).

After 60 days of incubation, seeds were opened to quantify necrotic embryos (Figure $3 \mathrm{~A}$ ). Necrotic embryos were respectively $7.2 \pm 1.3 \%$ in group $1,6.6 \pm 0.5 \%$ in group 2 and $10.5 \pm 1.1 \%$ in group 3 . Especially in group 1 , NT and Cryo seeds were necrotic, respectively, for 8.0 \pm 2.3 and $5.0 \pm 1.0 \%$, in the group 2 , NT and Cryo seeds were necrotic, respectively, for $6.6 \pm 0.4$ and $6.6 \pm 1.0 \%$ and in the group 3, NT and Cryo seeds were necrotic, respectively, for $11.0 \pm 2.0$ and $8.0 \pm 1.3 \%$. Overall, the cryogenic treatment did not have significant effect on the necrotic status of the embryos.

As a result of the TTC test (Figure 3B), non-viable embryos were quantified as $2.0 \pm 0.4 \%$ and $4.0 \pm 1.0 \%$, respectively, in NT and Cryo seeds of Group 1, $13.0 \pm 2.1$ and $8.3 \pm 0.8 \%$ in NT and Cryo seeds of group 2 and 6.0 $\pm 1.0 \%$ and $4.0 \pm 1.0 \%$ in NT and Cryo seeds belonging to group 3 (no statistically significant differences identified). Collectively, these results confirm that the drastic drop of temperature induced by $L N$ does not negatively affect the viability of the embryos.

The acclimatization occurred successfully and both plants that originated from Cryo seeds incubated in water or $\mathrm{GA}_{3}$ developed similarly (Figure $2 \mathrm{G}$ and $\mathrm{H}$ ). It should be noted that despite the fact that leaves of seedlings germinated from $\mathrm{GA}_{3}$-incubated seeds appeared scrubbier when compared to the water control seeds, at later stages of growth, plants were morphologically undistinguishable (Figure 2l).

\section{DISCUSSION}

The amount of seeds per samara is an important parameter to be considered in order to collect the appropriate amount of fruits for gene bank preservation purposes. The samaras collected in these study contained seeds in percentages ranging from 93 to $97 \%$. Seed of $F$. angustifolia are typically characterized by a shallow degree of dormancy, as proposed by Piotto and Piccini (1998), which still observed both morphological and physiological dormancy; on the other hand, Raquin et al. (2002) considered the dormancy as an effect of either tegument or endosperm inhibition.

In our experiments, seeds harvested at dispersal time appeared complete and homogenous in size, without any observable morphological dormancy. Any mechanical resistance opposed by the enveloping tissues of the embryo to germination could also be excluded. Seeds collected in July, at early stage of maturation, exhibited exclusively a physiological dormancy which could be broken by gibberellin addition. The seeds collected in November, during the final stage of maturation, after desiccation to $3 \% \mathrm{MC}$ did not show any dormancy. In contrast, seeds collected also in November but desiccated to $6 \%$ MC underwent physiological dormancy, as indicated by the significantly lower germination percentage in water $(44.0 \pm 2.4)$, which could be reverted by the addition of $\mathrm{GA}_{3}$ up to $74.0 \pm 5.0$.

The physiological dormancy was significantly stronger in seeds collected in July with respect to those collected in November, suggesting a loss of dormancy during seed maturation. Furthermore, seed MC interfered with the germination process or the dormancy break and we suggest a dormancy-inhibitory effect of $3 \% \mathrm{MC}$. The lack or shallow dormancy observed in $F$. angustifolia is in agreement with the studies by Piotto and Piccini (1998) for two reasons. First, the germination occurred easily without pre-treatment when seeds were sowed in autumn. Second, Piotto and Piccini (1998) observed in Italy a trend of dormancy of $F$. angustifolia seeds which decreased with decreasing latitudes. Accordingly, experiments were conducted at even lower latitudes (Sicily) thereby explaining the decreased dormancy level observed. The Sicilian $F$. angustifolia does not need any stratification pre-treatment, as reported by other authors (Piotto and Piccini, 1998; Steinbauer, 1937). A similar behaviour, that is, lack or low dormancy and no stratification requirement, is supposed for the seeds of $F$. angustifolia at same latitude or similar ecological conditions.

The constant temperature of $20^{\circ} \mathrm{C}$ was optimal for the germination, in contrast with Piotto (1994) that found this temperature to inhibit germination and furthermore induced secondary dormancy.

To our knowledge, ash cryopreservation experiments were conducted on dormant buds of $F$. pennsylvanica Marshall, F. mandshurica Rupr. and F. chinensis Roxb. (Volk et al., 2009) and on intact seeds (Chmielarz, 2009), zygotic embryos (Brearley et al., 1995), embryogenic callus (Ozudogru et al., 2010) and shoot tips (Schoenweiss et al., 2005) of $F$. excelsior. It is not reasonable to suppose a similar behaviour between $F$. angustifolia and $F$. excelsior seeds after cryopreservation treatment. In fact the development degree of the embryos is very different between the two species, the dormancy degree of $F$. excelsior is greatly stronger as compared to $F$. anfustifolia (Piotto and Piccini, 1998; Raquin et al., 2002). 


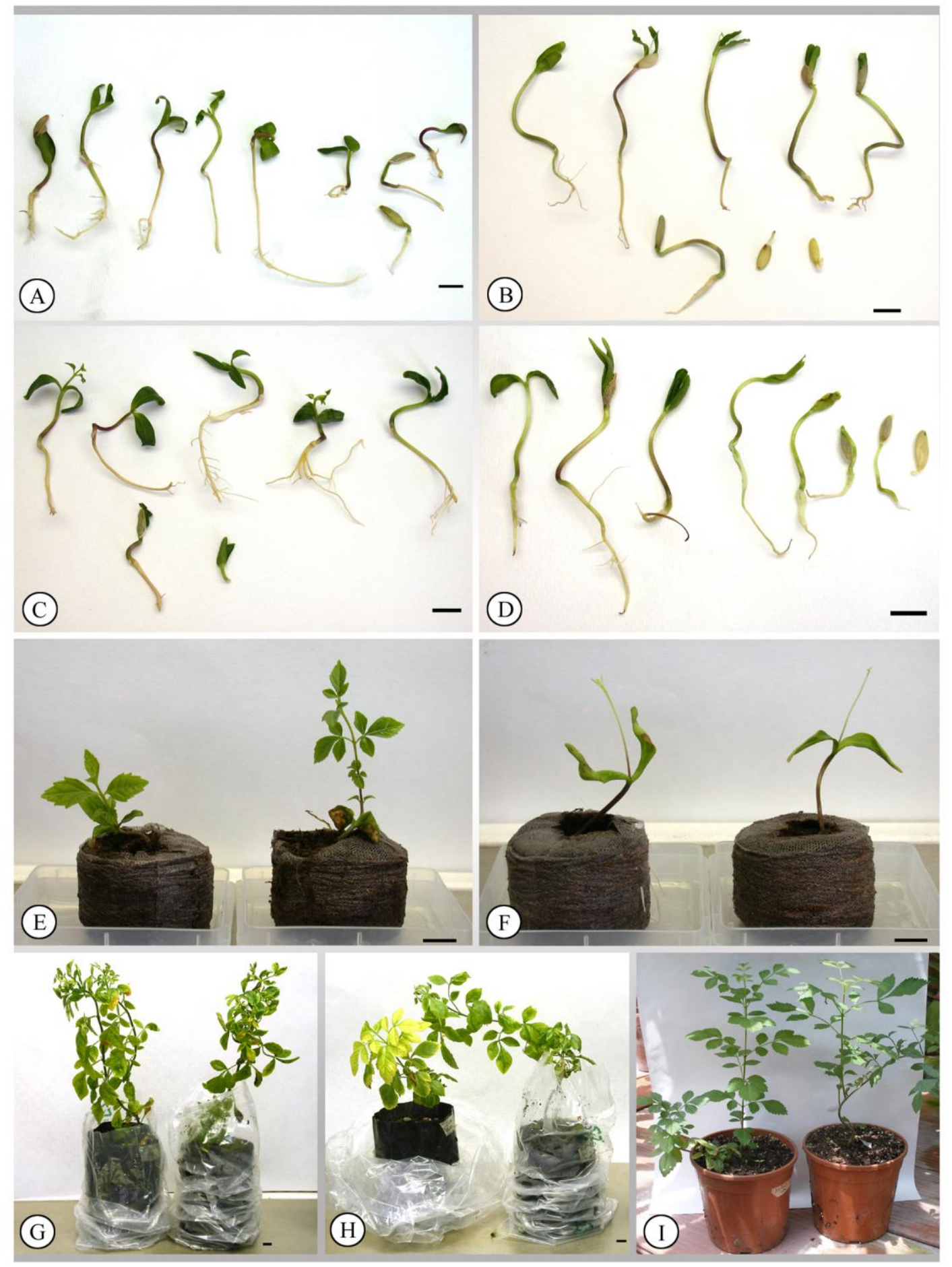

Figure 2. Developed seedlings of not treated seeds incubated in water $(A)$, in $G_{3}(B)$ and of cryopreserved seeds incubated in water (C) and in $\mathrm{GA}_{3}(\mathrm{D})$ for 30 days, seedlings of about 45-day-old transferred to Jiffy ${ }^{\circledR}$ substrate and developed from cryopreserved seeds incubated in water (E) and in $\mathrm{GA}_{3}(\mathrm{~F})$, four-month-old potted plants developed from cryopreserved seeds incubated in water $(\mathrm{G})$ and in $\mathrm{GA}_{3}(\mathrm{H})$ and potted plants of seven-month-old (I). Bar $1 \mathrm{~cm}$.

The results demonstrate the possibility to cryopreserve successfully the seeds of $F$. angustifolia. There was no significant effect of the cryopreservation treatment; in fact, both germination percentages and viability of embryos, revealed by TTC test, were statistically alike between the not treated and the treated seeds. As occurred 

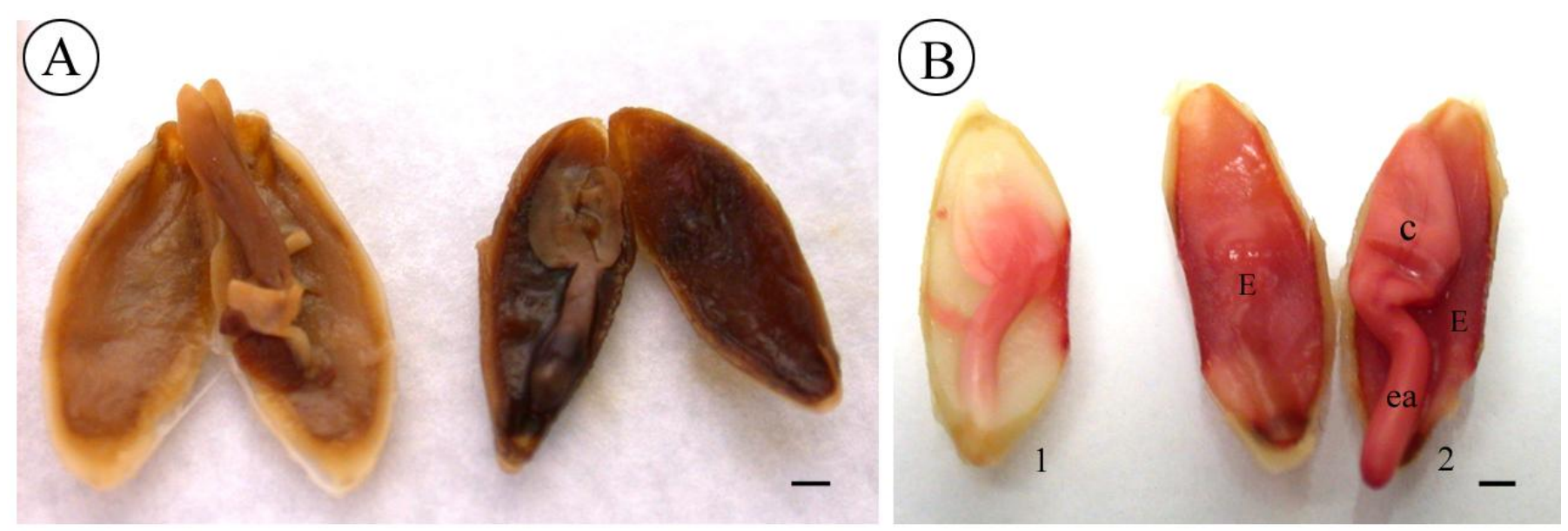

Figure 3. Necrotic embryos (A) and seeds stained with 1\% TTC solution (B). 1, not viable; 2, viable embryos; $\mathrm{c}=$ cotyledons, $\mathrm{E}=$ endosperm; ea = embryo axis. Bar $1 \mathrm{~mm}$.

in not treated seeds, also in cryopreserved seeds, gibberellin addition had a significant effect on germination of seeds collected in July and in November desiccated to $6 \% \mathrm{MC}$, while there was no significant effect of gibberellin only in cryopreserved seeds collected in November and desiccated to $3 \% \mathrm{MC}$. The use of full mature seeds cryopreserved with $3 \% \mathrm{MC}$ would avoid the addition of gibberellin, that at the beginning of the plant growth, had a negative effect on epicotyl development (longer than controls) and on the leaves that were scrubby. The seeds collected in July were able to be cryopreserved with $6 \%$ $\mathrm{MC}$, but to induce germination, the addition of gibberellin is essential. The possibility to cryopreserve these seeds could eliminate the risk of losing the samaras due to early dissemination.

Roots and hypocotyls length were normal without any significant difference among all the thesis of treated and not treated seeds. To cryopreserve, the safe range of 3 to $6 \% \mathrm{MC}$ in $\mathrm{F}$. angustifolia seeds is in agreement with the results of Pritchard and Nadarajan (2008) that stated that $\mathrm{MC}$ lower or equal to $8 \%$ tend not to affect seed survival following cryopreservation, which is in contrast with $F$. excelsior seeds, in which MC inferior to $7 \%$ had a negative effect on the germination of cryopreserved seeds (Chmielarz, 2009).

In $F$. angustifolia, buds/shoots were successfully obtained by organogenesis (Tonon et al., 2001b) and somatic embryos by embryogenesis (Tonon et al., 2001a), so that these explants could be used in other experiments of cryopreservation if it is useful to maintain clonal lines. In germplasm conservation programs, it is important to preserve the genetic diversity and therefore to conserve the seeds which is important to ensure the biodiversity within the species.

In conclusion, the cryopreservation did not damage the seeds of $F$. angustifolia. The seeds can be harvested during the early stage of maturation and cryopreserved with $6 \% \mathrm{MC}$ or harvested during the final stage of maturation with $3 \% \mathrm{MC}$. In the first case, the risk of losing the seeds because of early dissemination is avoided, but the addition of gibberellic acid is required to obtain a germination percentage $>80 \%$. In the latter case, the germination is $70 \%$ and the addition of the growth regulator is not necessary. The seedlings grew regularly and developed into plants after potting and acclimatization. This protocol is very useful for the preservation of monumental specimens of $F$. angustifolia and finds applications in the germplasm conservation of this species.

\section{ACKNOWLEDGEMENTS}

This work was supported by Regione Sicilia (Programma per la Conservazione della Biodiversità Vegetale PSR 2007-2013).

\section{REFERENCES}

Bonner FT (2008). Storage of Seeds. In: Bonner FT and Karrfalt RP (eds), The Woody Plant Seed Manual. Agric. Handbook No. 727 Department of Agriculture, Forest Service. Washington DC. U.S. p. 86.

Brearley J, Henshaw GG, Davey C, Taylor NJ, Blakesley D (1995). Cryopreservation of Fraxinus excelsior L. zygotic embryos. CryoLetters 16:215-218.

Chetverikova EP (2008). Dehydration in cryopreservation of moist plant tissues and seed maturation. Biophysics 53: 304-307.

Chmielarz P (2009). Cryopreservation of dormant European ash (Fraxinus excelsior) orthodox seeds.

Tree Physiol. 29: 1279-1285.

Engelmann F (2004). Plant cryopreservation: Progress and prospects. In Vitro Cell. Dev. Biol. Plant 40: 427-433.

llardi V, Raimondo FM (1999). The genus Fraxinus L. (Oleaceae) in Sicily. Fl. Medit. 9:305-318.

Ozudogru EA, Capuana M, Kaya E, Panis B, Lambardi M (2010). Cryopreservation of Fraxinus excelsior L. embryogenic callus by onestep freezing and slow cooling techniques. CryoLetters 31:63-75.

Patil VN, Dadlani M (1993). Tetrazolium Test for Seed Viability and Vigour. Retrieved from http://dacnet.nic.in/seednet/seeds/Material/Handbook_of_seed_testin g/Chapter\%2014.pdf. 
Piotto B (1994). Effects of temperature on germination of stratified seeds of three ash species. Seed Sci. Technol. 22: 519-529.

Piotto B, Piccini C (1998). Influence of pretreatment and temperature on the germination of Fraxinus angustifolia seeds. Seed Sci. Technol. 26:799-812.

Popov AS, Popova EV, Nikishina TV, Vysotskaya ON (2006). Cryobank of plant genetic resources in Russian Academy of Sciences. Int. J. Refrig. 29:403-410.

Preece JE, Bates SA, Van SJW (1995). Germination of cut seeds and seedling growth of ash (Fraxinus spp.) in vitro. Can. J. Forest Res. 25:1368-1374.

Pritchard HW, Nadarajan J (2008). Cryopreservation of orthodox (Desiccation Tolerant) Seeds. In: Reed BM (ed), Plant Cryopreservation: A Practical Guide. Springer. USA. p. 488.

Raquin C, Jung-Muller B, Dufour J, Frascaria-Lacoste N (2002). Rapid seedling obtaining from European ash species Fraxinus excelsior (L.) and Fraxinus angustifolia (Vahl). Ann. For. Sci. 59:219-224.

Roberts EH (1973). Predicting the storage life of seeds. Seed Sci. Technol. 1:499-514.

Schicchi R, Camarda L, Spadaro V, Pitonzo R (2006). Caratterizzazione chimica della manna estratta nelle Modonie (Sicilia) da cultivar di Fraxinus angustifolia e di Fraxinus ornus (Oleaceae). Quad. Bot. Amb. Appl. 17:151-174.
Schoenweiss K, Meier-Dinkel A, Grotha R (2005). Comparison of cryopreservation techniques for long-term storage of ash (Fraxinus excelsior L.). CryoLetters 26:201-212.

Steinbauer GP (1937). Dormancy and germination of Fraxinus seeds. Plant Physiol. 12:813-824.

Tonon G, Berardi G, Rossi C, Bagnaresi U (2001a). Synchronised somatic embryo development in embryogenic suspensions of Fraxinus angustifolia. In Vitro Cell. Dev. Biol. Plant 37:462-465.

Tonon G, Capuana M, Di MA (2001b). Plant regeneration of Fraxinus angustifolia Vahl by in vitro shoot organogenesis. Sci. Hortic. 87:291301.

Volk GM, Bonnart R, Waddell J, Widrlechner MP (2009). Cryopreservation of dormant buds from diverse Fraxinus species. Cryoletters 30:262-267.

Walters C, Wheeler L, Stanwood PC (2004). Longevity of cryogenically stored seeds. Cryobiology 48:229-244. 